\title{
Quest for Pragmatic Solutions to Complex Environmental and Health Problems of Small Scale Mining (ASM): Second IGCP-SIDA- UNESCO Project 606 Report
}

\author{
27-30 June, 2012, Kumasi, Ghana
}

\section{Introduction}

The purpose of the workshop was: (1) to assess the nature and extent of the health and environmental effects of small-scale mining; (2) to identify and appraise current small-scale mining and processing technologies, with respect to the health of miners and nearby residents; (3) to share knowledge and experience on the major challenges of artisanal and small scale miners in SubSaharan Africa; (4) to discuss the successes and shortcomings of efforts to "regularize" ASM and come up with an effective roadmap for raising the profile of small-scale mining; (5) to recommend appropriate intervention measures and support systems as vehicles for maintaining public health, poverty alleviation and sustainable small-scale mining, and (6) to review the role and work of the International Union of Geological Sciences (IUGS) and provide recommendations for its future direction.

The workshop attracted a group of about 45 interdisciplinary participants (Figure 1), mainly from the 'geosciences', from Ghana, Kenya, Cameroon, Nigeria, South Africa and Zimbabwe. The deliberations of the workshop were covered in the following sessions: An 'Opening Ceremony'; six
'Scientific Sessions'; a 'Field Visit' to two small-scale mining operations at Dwenase, in the Bekwai District of the Ashanti Region in Ghana; a 'Business Meeting', and a 'Workshop Summary and Resolutions' Session.

An exciting and warm welcoming speech was delivered to all participants by Dr. S.K.Y. Gawu.

Chairman's Opening Remarks, given by Prof. Mohammed Salifu, representing the Provost, College of Engineering of the Kwame Nkrumah University of Science and Technology (KNUST). The speaker emphasized the aims of the workshop and raised concerns which needed to be addressed, such as damaging health consequences of mining activities: public health, safety and preservation of environmental health integrity. He pointed out the challenges faced in this sector: socioeconomic benefits vis a vis, the cost on health. Further, he encouraged the College of Engineering of KNUST to engage in relevant teaching and research towards reduction in negative impacts on the environment to benefit the immediate surroundings.

Welcome address was given by Mr. Kofi Dwomoh, the Ashanti Regional Coordinating

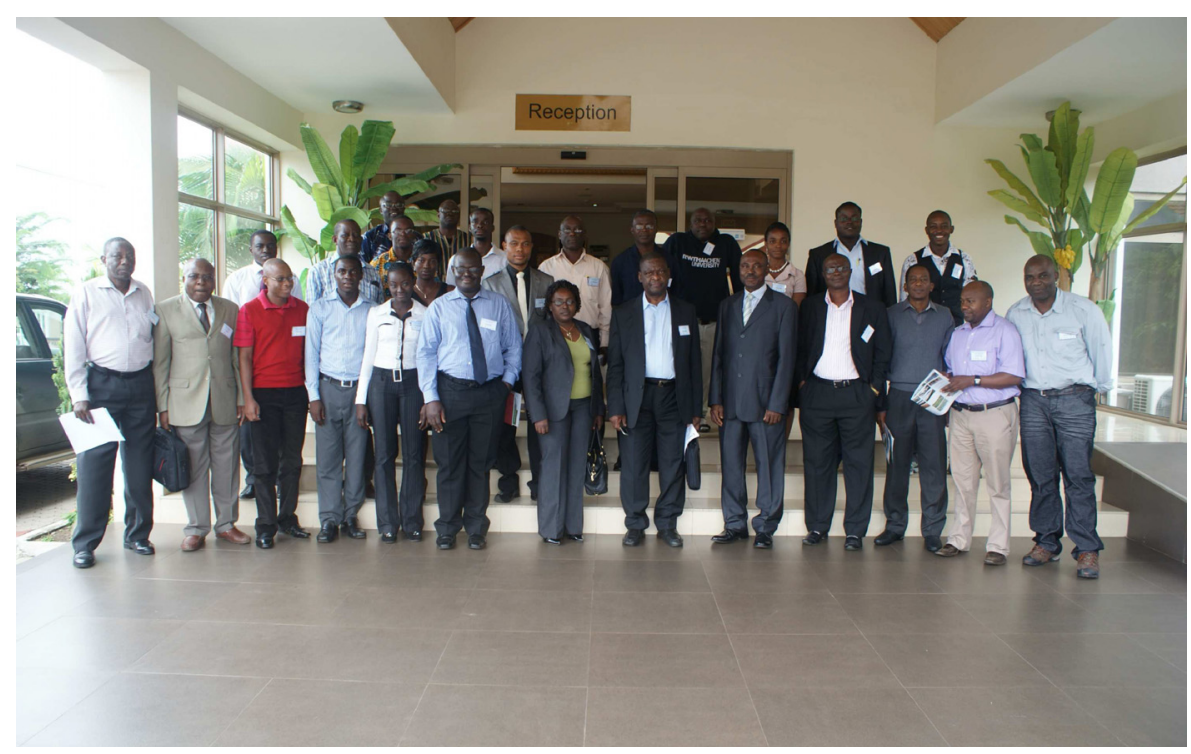

Delegates outside the Workshop Venue Hotel Noda, Kumasi, Ghana
Director, representing the Ashanti Regional Minister. He stated that despite positive aspects concerning the gains from mining, the disadvantages remain, not only to the environment and human health, but also negative social effects. The speaker pointed out that the Government of Ghana and the people of Ghana are increasingly concerned with ASM and emphasized the aims and objectives of the workshop.

\section{Overview of IGCP Project 606}

Prof T.C. Davies gave an overview of IGCP Project 606. He recognized all the stakeholders in the workshop and other major players, including the University of Venda in South Africa. He re-iterated the advantages derived from mining by the Sub-Saharan African economies, and also the disadvantages posed to the environment and human health. The consequences of use of improper mining methods, he emphasized, included soil erosion that affects agriculture and pollution of water resources (both surface- and underground water supplies) by metal releases from mines. He appreciated and extended a warm welcome to all participants to the UNESCO Project 606, reminded the participants of the appropriateness of the theme for the year 2012, viz., 'The quest for pragmatic solutions to complex environmental health problems of small-scale mining".

He encouraged graduates to address the health impacts of mining as keenly as possible in Kumasi, and continue to work consistently when they return home, towards reducing the negative impact of mining on the environment by using sound and environmentally friendly techniques and equipment in their respective countries.

\section{Keynote Address}

Mr. Joseph Abew, Principal Officer (Minerals Commission) in Charge of Small Scale Mining in Greater Parts of Ashanti Region, re-echoed the importance of mining activities, bearing in mind the environmental impacts on the health of humans. $\mathrm{He}$ mentioned the need for continual EIA in the 
environment to ensure safety and a healthy environment.

Dr. Felix Toteu, UNESCO's Earth science representative for Africa presented an overview of UNESCO's 'Earth Science Education Programme in Africa'. Dr. Toteu expounded the role of UNESCO in supporting the myriads of Earth science projects, and presented UNESCO Nairobi Office's broad mandates and policies towards the Earth Sciences in Africa. He recounted steps taken by UNESCO to redress the paucity of Africa's science contribution to IGCP projects, and stressed the need for networking, that involves major geoscientific and mining institutions, for the success of this important Project (606) on major and abandoned mines of Sub-Saharan Africa.

Prof. Mohammed Salifu in his closing remarks pointed out UNESCO's emphasis on education and its focus on environmental conservation/preservation, as well as sustainable development at all levels, which should be engaged effectively. He stated that the IGCP 606 Project has direct bearing on developmental challenges in Africa. He wished all a fruitful discussion, marked by innovative approaches to finding solutions to environmental problems associated with mining activities.

Vote of thanks given was proposed by a young geological engineer, Ms. Henrieta Poku-Asare of KNUST.

\section{Scientific Session 1: Socio-economic and environmental impacts of small-scale mining}

In the first paper, Abbey et al. pointed out the need to diversify farming to assist in reducing poverty levels in the Kui community, as well as reduce dependence on mining, in the northern region of Ghana. Lekmang and Dibal showed the relationship between economic, environmental and social impact of artisanal mining around Kuru-Jenta Village, Barkin-Ladi, Jos Plateau, Nigeria. The paper by Nghargbu et al. outlined the economic benefits and environmental impacts on small-scale mining in Nasarawa State, Nigeria. In Aboagye's paper, environmental and health hazards associated with surface mining in Ghana, were discussed.

\section{Scientific Session 2: Heavy metal pollution and exposure}

Ngure et al. discussed the input of heavy metals in soils, water and fish in a small-scale gold mining region in Migori, Nyanza
Province, Kenya. They discussed human exposure to lead and other potentially harmful elements associated with galena mining in New Zurak, Central Nigeria. Lar et al. showed that drinking water and food grains cultivated in and around the mining district are contaminated with $\mathrm{Pb}, \mathrm{Zn}, \mathrm{U}, \mathrm{Cd}$ and As. Ngozi-Chika, C.S., pointed out the need for toxicological centers to eliminate the problem of wrong diagnosis as often is the case. Masindi et al. indicated that modified bentonite clay can adsorb As, B, Cr, Mo and Se from coal fly ash leachates. Ameh discussed geochemical distribution of heavy metals in soil around Itakpe Iron Ore mining area using a statistical approach.

\section{Scientific Session 3: Heavy Metal Contamination}

Mutoti et al. showed that there was biomagnification of heavy metals in animals as a result of consuming contaminated drinking water and eating of grasses from abandoned New Union Gold Mine tailings in S. Africa. Muzerengi et al. established that $\mathrm{Ni}, \mathrm{Cu}, \mathrm{Mn}, \mathrm{Co}$, As and $\mathrm{Zn}$ could be used as pathfinder elements for gold mineralization at Black Mountain Prospect, Giyani Greenstone belt in S. Africa.

\section{Field Trips}

A field visit to two mining sites in Dwenase, Bekwai District, Ashanti Region, about $75 \mathrm{~km}$ north of Kumasi was organized during the morning hours of Friday, 29 June. The small-scale mining activities are undertaken along the river bed. The geology of the area comprises largely of metamorphic rocks, enriched in gold. The alluvial gold is obtained from weathered rocks. Mining involves river course diversion, removal of the overburden material for gold extraction, and later re-direction of the river course. Simple mechanization was performed with two heavy caterpillar machines being used for excavation (Figure 2). It was observed that none of the workers wore any protective gear, both the females and the males. It was recommended that assays could be carried out to ascertain the presence of gold in the quartz gravels that form part of the waste. The operator of the mining sites was advised to encourage others to form cooperatives, which would attract funding from the banks for better exploitation of gold. Further, grinding of tailings and recollection of the sand for further extraction of gold was emphasized to the miner.

\section{Business Meeting}

A Business Meeting was held at 18:00 hours on 29 June at Noda Hotel and was attended by 22 delegates, who deliberated inter alia on the following:

i A 'Special Issue' for contributions presented at the 'Kumasi Workshop' was proposed by Prof. Davies. He pointed out that there is strong collaboration between the two sister 'Projects' through exchange of papers and organizing joint meetings. The sister project being IGCP/SIDA 594.

ii Dr. Felix Toteu discussed the 'Infrastructure for Data Capture and Storage'.

iii Capacity Building: It was stressed that participation of graduate students need to be encouraged, and their contributions

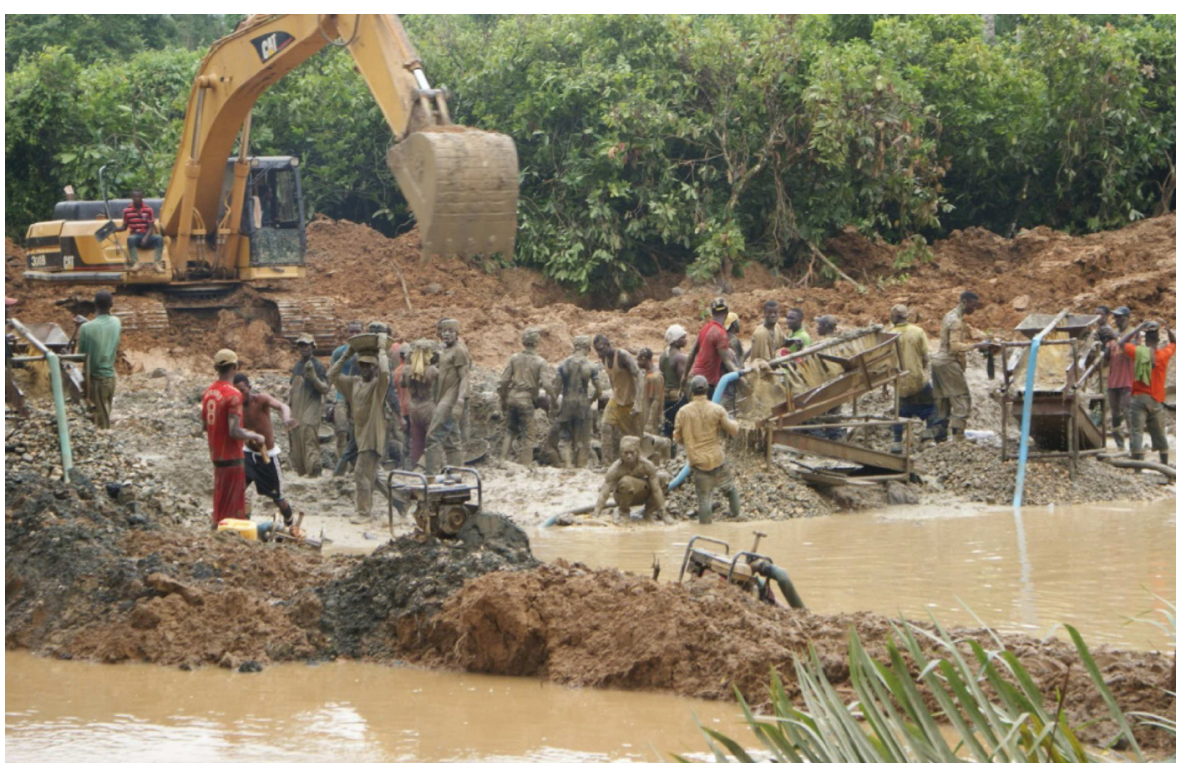

Figure 2. The small-scale mining activities being undertaken along the river bed. Simple mechanization is performed using a heavy caterpillar machine for excavation. 
solicited. Further, remarks on the quality of the work contributed so far by graduate students was mentioned. Student participation was noted as a very crucial aspect in UNESCO's agenda.

\section{Scientific Session 4: Environmental and Health Impacts of Aggregate Mining}

Prof. Davies presented an overview of Project 606, and spoke on 'Recent Advances in Mitigation and Rehabilitation Technology in Major and Abandoned Mines in SubSaharan Africa'. He emphasized mitigation and rehabilitation of mines in combating environmental health. He informed that the major aim of the project is to maximize benefits and minimize negative impacts on the environment. The paper discussed the impacts due to use of unsatisfactory mining methods and mineral processing operations, as well as dangers posed by abandoned mines. He then posed mind-searching questions such as: "What do we know about the relationship between mining, the fecundity of cultivable lands in the vicinity of mines, and therefore agriculture, which is the backbone of most African countries, and environmental health? What steps need to be undertaken towards addressing the issues?"

In the paper by Manakana et al. on "The impact of Bestaf Granite Mine on the Environment and Community Health and Safety at Kaditshwene Village in Limpopo Province of South Africa”, strategies on reduction of dust impacts and control techniques were discussed. A case study of the effects of mine dust on human health by Momoh et al. indicated that continuous inhalation could result in pulmonary fibrosis, among other respiratory disorders, and emphasized the need to have in place the necessary control measures that would drastically reduce suspended particulate matter in the air, such as wet drilling. Moeng and Shima pointed out that the concentration of heavy metals and high alkalinity present in the soil, endanger the life of plants and animals, as well as human health, in the stony lime quarry in the NW province of South Africa. In the paper by Benin and Gawu, the dangers posed by dimension stone production on the environment in Ghana was presented. Researchers revealed that there was no major environmental impact from the production of dimension stone.

\section{Scientific Session 5: Assessment and Mapping of Hazards.}

The first paper in the session by Okunlola and Soetan showed the possible anthropogenic input of selected heavy metals from iron ore mining site of Itakpe Okene, Central Nigeria into surface water and stream sediments could harm the environment. This paper was followed by Jerie's discourse on 'ergonomics- related hazards associated with trackless mining equipment underground', which included restricted vision, exposure to whole body vibration and advantages of applying sound ergonomics principles in small-scale mining. Mhlongo and Dacosta reported that the method which employs "hazard score" and "risk ranking" coupled with the use of "hazard maps", would provide a more robust scientific basis for making sound decisions and prioritizing actions that need to be followed to minimize or manage risks associated with activities at mine sites. The paper by Obiora discussed the delineation of sites where possible environmental/health problems are associated with mining activities in Nigeria.

\section{Scientific Session 6: Mine Water-related Issues}

Nghargbu et al. gave an appraisal of thermal springs in Benin, Niger and Nigeria in West Africa, which are used for medicinal purposes. He suggested possible ways of making the springs safe for use by the communities within their vicinities. Ntifori presented a paper on water quality conditions of an abandoned mine paddock for conversion into a fish pond. Gitari's paper focused on 'acid mine drainage formation, its environmental concerns, and the need for costeffective remediation'. The investigations showed that bentonite clay has great potential for use in treating moderately polluted mine water.

\section{Workshop summary and resolutions}

- The need to diversify interest of miners to other economic interests such as farming, to reduce the stress on the environment. This also provides an opportunity to guarantee sustainable and reliable income.

- The remediation of active and abandoned mine sites using appropriate cost effective technology such as bentonite clays /coal fly ash to remove heavy metals.

- Use of pathfinder elements in mineral exploration programmes.

- Quarry operations and mine dust constitute serious health hazards to miners.

- There is need to map, keep inventory and classify mining sites into active or abandoned, for consistent monitoring of education on environmental health hazards.

- There is need to explore the possibility of abandoned mine resources for useful economic purposes such as use of mine paddocks for fish keeping.

In conclusion, it could be said that the workshop achieved the objectives set out, in 'Scientific Sessions'. It was highly interactive and the debates were very lively. The need for further collaborative and interdisciplinary studies to unravel unclear relationships between mining and environmental health in Sub-Saharan Africa was clearly brought out. The intensity of research on improvement in mitigation and rehabilitation strategies by large mining concerns augurs well for the environmental health of miners and the surrounding mining communities.

\section{Acknowledgements}

The project leaders of IGCP/SIDA/ UNESCO Project 606 and UNIVEN Project SES/11/MEG/03/KNUST would like to express their profound gratitude to the Kwame Nkurumah University of Science and Technology for their kind help in hosting this important workshop. Dr. S.K.Y. Gawu of KNUST and his 'Organizing Committee' took care of all arrangements regarding workshop facilities in Kumasi, and did a superb job in the organization of the field visit to small-scale mining sites in Dwenase, Bekwai District, Ashanti Region. Project 606/ SES/11/MEG/03 is sponsored jointly by IGCP, SIDA, UNESCO and the University of Venda. Financial administration was done by the Finance Department of the University of Venda. We extend our sincere thanks to all these individuals and institutions for their tremendous support.

\section{Compiled by}

Veronica. Ngure (PhD),

Laikipia University College,

Egerton University,

Kenya

Prof. T.C. Davies (PhD),

University of Venda,

South Africa

\section{F. Amponsah-Dacosta $(P h D)$,}

University of Venda,

South Africa 